\title{
Hand Grip Strength and Older Adults: Is Hand Grip Strength Associated with Self-Efficacy in Older Adults?
}

\author{
Rebecca D. Belka, Mark DeBeliso* \\ Department of Kinesiology and Outdoor Recreation, Southern Utah University, Cedar City, USA \\ *Corresponding author: markdebeliso@suu.edu
}

Received November 19, 2018; Revised December 28, 2018; Accepted January 19, 2019

\begin{abstract}
Prior research indicates that older adult's grip strength is associated with overall body strength and the ability to perform functional tasks. Likewise, research indicates that those with a fear of falling are less likely to participate in the rigorous physical activities that would strengthen their muscles and reduce their risk of falling [1]. Hence, the purpose of this study was to determine if there was a meaningful relationship between grip strength and self-efficacy with regards to falling in older adults. The participants were male and female adults $\geq 65$ years of age $(\mathrm{n}=35)$. Each completed the FES-I survey to assess their fear of falling. Maximal grip (MG) strength (Kg) was then assessed with the Jamar hand grip dynamometer. MG scores were then converted to Newtons $(\mathrm{N})$, normalized to body mass, and then allometrically scaled to body mass and height. FES-I scores were then compared with Pearson correlation coefficients ( $\mathrm{r}$ ) with the various metrics of MG. Results demonstrated moderate to nearing strong significant negative relationships between FES-I scores and MG metrics ranging from $r=-0.36$ to $-0.44(p<0.05)$. Thus, it was concluded that stronger adults have a lower fear of falling than their weaker counterparts. It is postulated that older adults with a lower fear of falling will continue to engage in exercise which in turn will help maintain their strength levels and perpetuate continued exercise. Conversely, older adults with a greater fear of falling (i.e. lower strength levels) will disassociate from exercise, hence leading to even lower strength levels.
\end{abstract}

Keywords: Jamar, older adult, self-efficacy, grip

Cite This Article: Rebecca D. Belka, and Mark DeBeliso, "Hand Grip Strength and Older Adults: Is Hand Grip Strength Associated with Self-Efficacy in Older Adults?” Journal of Physical Activity Research, vol. 4, no. 1 (2019): 41-46. doi: 10.12691/jpar-4-1-4.

\section{Introduction}

In the year 2010, only $13 \%$ of residents in the United States were over the age of 65. It is projected that by 2030 that number will jump to over $20 \%$ of U.S. residents being 65 years old or older [2]. As people age, natural changes take place biologically, psychologically and physiologically that can have an unfavorable impact on their lives [3]. As health complications increase, their self-sufficiency decreases. Additionally, a deterioration in health often results in increased falls with more severe outcomes [3]. In fact, throughout the world, $35-40 \%$ of those in this age group fall every year [4,5]. Injuries caused from falling result in serious health problems, not to mention the increase in healthcare costs for these people [5]. The World Health Organization cautions that if immediate preventive measures are not taken, the injuries resulting from falls could increase $100 \%$ by the year 2030 [5]. With such gloomy statistics it is very apparent that care needs to be taken to assist elderly adults to decrease their risks for falling.

Halaweh et al. [6] point out several factors that predict falls in the elderly. First is the physical functioning level of an individual. Those who function at a low physical level and/or have a weak lower body are more likely to fall. Next, those who are afraid of falling have less leaning balance and an inadequate gait which contribute to falling. And finally, poor grip strength has been found to be a common factor in the elderly who have fallen. Interestingly, grip strength correlates strongly with overall body strength and the ability to perform functional tasks $[7,8]$. Similarly, there is a correlation between feeble muscles and an elderly person's risk of falling $[9,10]$. Additional factors that increase the older person's risk for falling include inadequate balance $[3,11]$ and the inability to effectively control their body when making transitions between various physical activities [12,13].

As noted above, the fear of falling affects gait and leaning balance in some elderly individuals [6]. It has been surmised that between $20 \%$ and $85 \%$ of elderly adults fear falling. This fear intensifies in those who have a history of falling $[3,14,15]$. When an elderly person has a fear of falling, they often restrict or avoid activities. This not only decreases muscle strength, but it can cause mental depression and impede their preferred lifestyle $[13,16]$.

It seems reasonable that reducing the fear of falling may lead to a reduction in the likelihood of falling for these individuals. Bandura's self-efficacy theory indicates that self-efficacy is an individual judging how competently 
they could carry out certain tasks $[17,18]$. This includes the individual's ability to cope with the situation, how much effort it will require and how long they will be able to sustain that effort. It was further pointed out that those who have a high level of self- efficacy can put in a substantial enough effort that the task is carried out successfully. Those with a low level of self- efficacy are prone to giving up early, thus failing at the task [17].

Other studies similarly show that elderly adults are affected by their level of self-efficacy and their strength. In a study conducted by Barakat et al [18], they noted that for the elderly to be comfortable participating in physical activity they need to have a high level of confidence in their ability to participate in it. Similarly, Tarsuslu-Şimşek \& Yanardag [19] point out the sense of well-being in older men and women directly correlated to the strength of their biceps brachia muscle: the stronger their upper limbs, the greater their measure of independence. An easy and substantiated method for assessing overall body strength in older adults is by testing the strength of their hand grip [20]. It has been shown that hand grip strength not only correlates closely with overall body strength, but also with functional body movements [7]. Of particular interest concerning the elderly is whether or not their self-efficacy is affected by their body strength. According to Prata and Scheicher [1] those with a significant fear of falling participate in less activities which further reduces their strength. So, do stronger elderly adults have a higher selfefficacy? The purpose of this study is to find the answer to that question by measuring grip strength and comparing it to their self-efficacy as assessed by the Falls Efficacy Scale-International instrument (FES-I).

\section{Methods}

\subsection{Participants}

This study involved participants who were 65 years of age or older. Both men $(n=14)$ and women $(n=21)$ were included. They were recruited via word of mouth and public announcements. All volunteers were community-dwellers who lived independently. All participants were given the option to read about the details of the study, but most chose to be verbally informed. Before the study began, volunteers gave their consent by signing the document which was authorized by the Institutional Review Board for the use of Human Subjects.

\subsection{Hand Grip Strength Assessment}

The Jamar hand dynamometer was used to assess maximal grip strength (MG). Each volunteer alternated between the right and left hands for a total of three trials per hand. The dynamometer was set at position 2 . Trampisch, et al [22] found that from a test group of 50 volunteers, $70 \%$ performed their greatest MG score when the dynamometer was set at position 2 .

Participants sat comfortably with their elbow flexed at 90 degrees, as suggested by Bellace et al [23]. Participants were given the opportunity to grip the dynamometer prior to the trial in order to become familiar with the device. To begin the trial, they were told to squeeze the dynamometer with maximal force for about 3 seconds. The grip was alternated between hands so that each hand could rest while the opposite hand performed the trial and the results were recorded. Of the three trials, only the strongest MG was used in analyzing the data.

The Jamar dynamometer was used for this research study because it is considered the "gold standard" in hand grip dynamometers and numerous studies have been conducted which demonstrate its competence [23,24]. Bellace et al. [23], showed the Jamar to be a highly reliable (ICC $=0.98$ ) assessment tool for measuring MG. Being a gold standard, it has also been tested against other handgrip devices to test their validity and reliability [24,25].

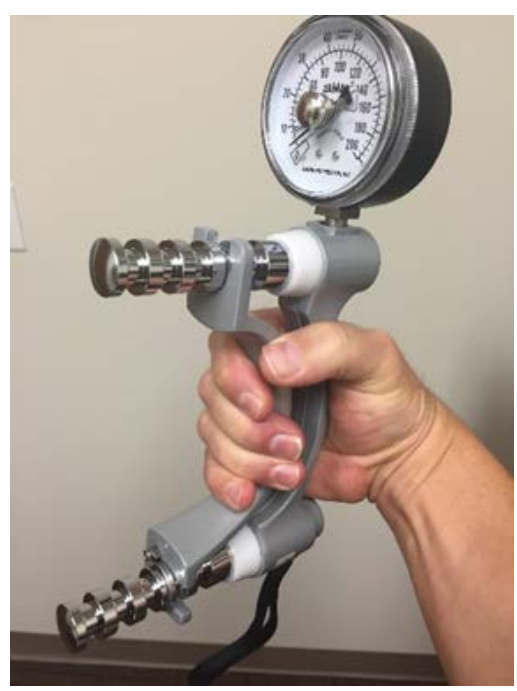

Figure 1. Jamar Dynamometer (Image reprinted with permission from Layton et al. [21].)

\subsection{Fear of Falling Assessment}

In order to effectively assist elderly and understand their fear of falling, it became apparent that a questionnaire was needed that was not only sensitive enough to differentiate the intensity of their fears about falling, but also showed the level of concern they had about participating in various activities [26]. Thus, the first Fears Efficacy Scale (FES) was developed [26,27]. It measures how confident a person feels about performing daily tasks without falling. The reliability of the FES is excellent and has a high correlation with measurements of gait and balance [26,27,28]. Additionally, it can predict the potential for future falls, as well as a deterioration in one's ability to function [26,27,29,30,31,32]. Of particular importance, once a person has participated in clinical interventions, the FES is able to show a change in their fears [26,33-36]. Despite the benefits of the FES, some felt that it could still be improved upon [26].

The three main concerns with the FES were as follows: First, it did not necessarily specify a person's anxiety about participating in a task, nor did it indicate their selfefficacy, or confidence, that they could perform a task without falling. Rather, the participant gave more of an estimate of their functional ability to do the task [26,37]. Next, the original FES only asked questions about very basic daily activities that perhaps very feeble or disabled adults would be concerned about. Those questions were 
rather irrelevant to the more active older adults. As a result, it did not help predict falls in those who were higher functioning [26,38]. Finally, the original FES did not assess how one's fear of falling might affect their social life [26,39].

Thus, the FES was modified. According to Yardley et al [26], the improved Falls Efficacy Scale-International (FES-I) is more suitable to be translated into a variety of languages and used across cultures. It includes social situations and more difficult activities. The FES-I was created by members of the Prevention of Falls Network Europe who met several times to develop it [26]. The FES-I has excellent internal reliability (Cronbach's alpha $=0.96)$ and test-retest scores (ICC $=0.96)[26,40]$.

The Falls Efficacy Scale-International (FES-I) is a simple, straight forward survey [40]. Participants are asked to rate their fear of falling while participating in 16 common daily activities which they may or may not engage in. Participants assess their concerns using a 4-point scale as follows: 1=not concerned, 2=somewhat concerned, 3=fairly concerned, 4=very concerned [26,40]. After the points are scored, a rating, as shown by Delbaere et al [41], is assigned as follows:

- Low concern about falling: 16-19

- Moderate concern about falling: 20-27

- High concern about falling: 28-64.

\subsection{Allometric Hand Grip Strength}

MG was originally assessed and recorded in kilograms (kg), but later changed to Newtons (MG kg x $9.81 \mathrm{~m} / \mathrm{s}^{2}$ ). Similar to the process employed by Sevene et al [42], the following equations were used to normalize the scores allometrically, as referenced by Jaric et al [43] and Maranhao Netoa et al [44]:

- $\mathrm{MG}_{\mathrm{n}}=\mathrm{MG}(\mathrm{N}) /(\text { body mass kgs })^{0.67}$

- $\mathrm{MG}_{\mathrm{n}}=\mathrm{MG}(\mathrm{N}) /\left(\right.$ body height meters) ${ }^{1.84}$.

\subsection{Statistical Analysis}

Pearson Correlation Coefficients (r) were employed to examine the relationship between the FES-I scores and the measures of hand grip strength as described above. The strength of the PCC's was then assessed as described by Cohen 1988 [45]. The significance for the study was set at $\alpha \leq 0.05$.

\section{Results}

All 35 participants completed the MG trials and the FES-I without complication. The female $(n=21)$ age, body mass, height, and FES-1 scores are as follows: 72.5 \pm 4.5 yrs, $75.2 \pm 18.4$ kgs, $1.63 \pm 0.07$ meters, 26.9 \pm 9.4 . The male $(n=14)$ age, body mass, height, and FES-1 scores are as follows: $75.6 \pm 5.2 \mathrm{yrs}, 96.3 \pm 18.3 \mathrm{kgs}, 1.78 \pm 0.07$ meters, and 22.9 \pm 6.6 .

Table 1 shows the participants' MG strength in kg (mean \pm standard deviation), then converted to Newtons. It also shows their MG strength (kg) divided by their body mass (kg), (mean \pm standard deviation). To standardize the results between male and female participants the results were allometrically scaled for body mass (mean \pm standard deviation) and body height (mean \pm standard deviation). For the FES-I, Pearson's correlation coefficient ranged from $r=-0.36$ to -0.44 . According to Cohen [45], these correlations are considered moderate to nearing strong, noting that the negative sign indicates that greater grip strength is associated with a lower fear of falling.

Table 1. Grip Scores

\begin{tabular}{lcccc}
\hline Measure & $\begin{array}{c}\text { Male } \\
(\mathbf{n}=14)\end{array}$ & $\begin{array}{c}\text { Female } \\
(\mathbf{n}=\mathbf{2 1})\end{array}$ & Total (n=35) & PCC \\
\hline MG (kg) & $42.6 \pm 6.6$ & $24.4 \pm 6.8$ & $31.7 \pm 11.2$ & $-0.36^{*}$ \\
MG (N) & $418.3 \pm 64.8$ & $238.9 \pm 66.6$ & $310.7 \pm 110.3$ & $-0.36^{*}$ \\
$\begin{array}{l}\text { MG (kg)/body } \\
\text { mass (kg) }\end{array}$ & $0.45 \pm 0.06$ & $0.33 \pm 0.09$ & $0.38 \pm 0.10$ & $-0.44^{*}$ \\
$\begin{array}{l}\text { MG Allometric } \\
\text { scaled (N/kg) }\end{array}$ & $19.7 \pm 2.1$ & $13.3 \pm 3.4$ & $15.9 \pm 4.3$ & $-0.44^{*}$ \\
$\begin{array}{l}\text { Body Mass } 0.67 \\
\text { MG Allometric } \\
\text { scaled (N/meters) } \\
\text { Body Height }\end{array}$ & $144.2 \pm 20.1$ & $96.7 \pm 24.4$ & $115.7 \pm 32.6$ & $-0.43^{*}$ \\
\hline
\end{tabular}

Maximal Grip scores (mean $\pm \mathrm{SD}$ ). MG-maximal grip, kg-kilograms, $\mathrm{N}$-Newtons, PCC-between FES-I and grip measure, *Significant $\mathrm{P}<0.05$.

\section{Discussion}

The purpose of this study was to determine the correlation between max grip strength (MG) and self-efficacy with regards to falling among the elderly. Given the high degree of correlation between $\mathrm{MG}$ and overall body strength [7], it was hypothesized that individuals with a stronger MG would have a lower fear of falling (i.e. greater self-efficacy). Data collected from the current study supported the hypothesis. The data collected in the current study demonstrated a moderate to nearing strong negative correlation between MG and fear of falling, indicating that greater grip strength was associated with a lower fear of falling. This relationship persisted for all manners of reporting of MG (i.e. normalized to body mass, and allometrically scaled). In other words, the stronger a person is, the less they fear falling. This is critical to recognize because falls are a principal reason for hospitalization and even a prevailing cause of accidental death among the elderly [9,46,47].

The data collected in this study is supported by previous studies concerned with the elderly population; specifically their fear of falling and the impact that muscle loss has on their lives. A destructive cycle can occur when they decrease their activity because they fear falling. The reduction in activity level decreases their muscle strength, which not only increases their fear of falling [1], but also lays the foundation to losing their independence. In fact, it has been shown that loss of independence in older adults follows a hierarchical pattern that begins with a loss of mobility, followed by a decreased ability to participate in societal living, and finally losing the ability to fully care for self $[48,49]$. Both upper and lower body strength are important for preserving the ability of an individual to complete the tasks of daily living [19]. Upper body strength is necessary for day to day activities like taking a bath/shower, getting dressed, shaving, meal preparation, etc. Whereas, the lower limbs need to be strong so that ambulation and mobility are not compromised [19]. Additionally, a lack of 
strength in the lower limbs is a valid predictor of an individual being injured from a fall [6]. Once an elderly person falls, they often limit their activities in an effort to prevent future falls. This subsequent inactivity further weakens their muscles [1] which increases their risk of falling again.

It has been shown that the quality of one's muscles declines during the aging process, resulting in a considerable loss of strength [9,50,51]. Weakened muscles are a well-documented contributor to falling [9,52,53], and a condition that, in and of itself increases death rates among the elderly [54]. Similarly, Chipperfield [55] also found that sedentary adults are at a $3 x$ higher risk of dying than their more active counterparts.

The best way to apply the results of this study would be to use it as a way to help the elderly recognize that their overall body strength has a meaningful correlation with their fear of falling. However, simply encouraging the older population to participate in a more active lifestyle may not yield the desired results. Perhaps first helping them recognize their own level of confidence in carrying out daily tasks would be a good place to start, as demonstrated in the following study conducted by Prata and Scheicher [1]. Eleven elderly women who had previously fallen were evaluated using the FES-I. The FES-I helped determine the degree of concern they felt about falling again. Their mobility and muscle strength were also evaluated. After participating in a 12-week program in which they performed strength training and balance exercises twice a week, they were re-assessed. The women showed important gains in muscle strength and mobility. Correspondingly, their fear of falling declined.

Similar research agrees by indicating that a way to boost self-confidence in elderly people is to involve them in aerobic exercise or programs which increase flexibility and balance [3,56]. Furthermore, Huang et al [13], reported that because exercise improves muscle strength [57,58], it is a way to reduce the number of falls in elderly persons [58], and in turn may reduce their fear of falling [59]. It is evident that helping our elderly population maintain mobility will extend their life, keep them safe and improve the overall quality of their life. Concannon et al [60] reiterated that increasing muscular strength will decrease aging adults likely of becoming disabled, thus prolonging their independence. Concannon et al [60] also pointed out that being physically active can treat depression by boosting mood and improving psychological health. Likewise, participating in resistance training can increase bone mass density (which can prevent bone fractures) in the elderly as well as aid in preventing sarcopenia [60]. The authors [60] further contended that muscle atrophy in old age may be due to lack of use, rather than just the fact of aging. Finally, Concannon et al [60] promote aerobic exercise in the elderly, in part, to diminish the stiffness in the large arteries which can lead to cardiovascular disease in mature adults.

A limitation of the current study was that all the participants were from similar backgrounds. A more diverse study group would have greater relevance to a larger population. The participants were all white, middle-class, community dwellers with the oldest of them only being 77 years old. To improve future research, individuals from other races and socioeconomic statuses should be included. Additionally, including people in their 8th and 9th decades of life and those from assisted living facilities would add to the applicability of the study results. Finally, recent developments in grip analysis technology [61] may provide a better understanding of what aspects of grip strength are most related to self-efficacy as related to fear of falling.

\section{Conclusion}

Within the parameters of this study, it is concluded:

- Maximal hand grip strength is associated with self-efficacy as related to fear of falling regardless of the mechanism of MG reporting [MG (kg), MG (N), MG (kg) / Body Mass (kg), MG (N) / (Body Mass) $\left.^{0.67}, \mathrm{MG}(\mathrm{N}) /(\text { Body Height })^{1.84}\right]$

- Given the ease and low cost of assessing grip strength, it would appear a prudent test to administer to the aging population as part of an annual physical exam in order to gage self-efficacy and over all body strength.

\section{References}

[1] Prata MG, Scheicher ME. Effects of strength and balance training on the mobility, fear of falling and grip strength of elderly female fallers. J Body Mov Ther 2015; 19(4): 646-650.

[2] Ortman JM, Velkoff VA, Hogan H. An aging nation: The older population in the United States. U.S. Census Bureau. 2014; 1-28. Retrieved November 20, 2017.

[3] Okuyan CB, Bilgili N. Effect of tai chi chuan on fear of falling balance and physical self-perception in elderly: a randomised controlled trial. Turk Geriatri Der 2017; 20: 241-241.

[4] Ward RE, Leveille SG, Beauchamp MK, Travison T, Alexander N, Jette AM, Bean JF. Functional performance as a predictor of injurious falls in older adults. J Am Geriatr Soc 2015; 63: 315-20.

[5] World Health Organization. Ageing and Life Course. WHO Global Report on Falls Prevention in Older Age [Brochure]. 2008; Available from:

http://www.who.int/ageing/publications/

Falls_prevention7March.pdf.

[6] Halaweh, H, Willen C, Svantesson U, Grimby-Ekman A. (2016). Physical functioning and fall-related efficacy among communitydwelling elderly people. Eur J Physiother 2016; 18(1), 11-17.

[7] DeBeliso M, Boham M, Harris C, Carson C, Berning JM, Sevene TG, Adams KJ, \& Climstein M. Grip Strength and Functional Measures in the Mature Adult: Brief Report II. Int J Sci Eng Inv 2015; 4: 1-4.

[8] Semba RD, Cappola AR, Sun K, Bandinelli S, Dalal M, Crasto C, Guralnik JM, Ferrucci L. Relationship of low plasma klotho with poor grip strength in older community-dwelling adults: the In CHIANTI study. Eur J Appl Physiol 2011; 112: 1215-20.

[9] Gadelha AB, Neri SR, Nóbrega OT, Pereira JC, Bottaro M, Fonsêca A, Lima RM. Muscle quality is associated with dynamic balance, fear of falling, and falls in older women. Exp Gerontol 2018; 104: 1-6.

[10] Moreland JD, Richardson JA, Goldsmith CH, Clase CM. Muscle weakness and falls in older adults: a systematic review and metaanalysis. J Am Geriatr Soc 2004; 52: 1121-29.

[11] Maciaszek J, Osinski W. The effects of Tai Chi on body balance in elderly people a review of studies from the early 21st century. Am J Chin Med 2010; 38: 219-29. (PMID:20387220).

[12] Yo SH, Jwo HJ, Wu TY, \& Lin CE. The constraint perspective on falls and prevention strategies of falls among the older adults. Zhong Hua Ti Yu 2007; 21, 1832.

[13] Huang T, Chung M, Chen F, Chin Y, \& Wang B. Evaluation of a combined cognitive-behavioural and exercise intervention to manage fear of falling among elderly residents in nursing homes. Aging Ment Health 2015; 20: 2-12. 
[14] Apaydın K, Kırımlı E, Kalaça Ç, et al. The incidence of falls and related factors in the elderly living in residential homes. Turk Geriatri Der 2012; 15: 40-46. (in Turkish).

[15] Gillespie LD, Robertson MC, Gillespie WJ, Sherrington C, Gates S, Clemson LM, Lamb SE. Interventions for preventing falls in older people living in the community. The Cochrane Library 2012; 12(9): CD007146. (PMID:19370674).

[16] Lach HW, Parsons JL. Impact of fear of falling in long term care: An integrative review. J Am Med Dir Assoc 2013; 14: 573-577.

[17] Stajkovic AD, Luthans F. Self-efficacy and work-related performance: A meta-analysis. Psychological bulletin 1998; 124: 240.

[18] Barakat RA, Rech CR, Marshall ST, Benedetti TR. Validity and reliability of a scale for measuring self-efficacy for physical activity for the elderly. CAD, Saúde Pública 2015; 31.

[19] Tarsuslu-Şimşek T, Yanardag M. Muscle Strength and Independence for Older Individuals in Nursing Homes. Top Geriatr Rehabil 2017; 33: 255-61.

[20] DeBeliso M, Boham M, Harris C, Carson C, Berning JM, Sevene TG, Adams KJ. Grip and Body Strength measures in the mature adult: A brief report. Int J Sci Eng Inv 2015; 4: 83-6.

[21] Layton J, DeBeliso M. Is there a relationship between maximal grip strength and racquetball success? Athens Journal of Sports 2017; 4: 139-49.

[22] Trampisch US, Franke J, Jedamzik N, Hinrichs T, Platen P. Optimal Jamar dynamometer handle position to assess maximal isometric hand grip strength in epidemiological studies. $J$ Hand Surg Am 2012; 37: 2368-73.

[23] Bellace JV, Healy D, Besser MP, Byron T, Hohman L. Validity of the Dexter evaluation systems jamar dynamometer attachment for assessment of hand grip strength in a normal population. $J$ Hand Ther 2000; 13: 46-51.

[24] Svens B, Lee H. Intra- and inter-instrument reliability of grip-strength measurements: GripTrack ${ }^{\mathrm{TM}}$ and Jamar ${ }^{\circledR}$ hand dynamometers. The British Journal of Hand Therapy 2005; 10: 47-55.

[25] Hamilton GF, Mcdonald C, Chenier TC. Measurement of grip strength: Validity and reliability of the sphygmomanometer and Jamar grip dynamometer. J Orthop Sports Phys Ther 1992; 16: 215-19.

[26] Yardley L, Beyer N, Hauer K, Kempen G, Piot-Ziegler C, Todd C. Development and initial validation of the Falls Efficacy Scale-International (FES-I). Age Ageing 2005; 34: 614-19.

[27] Tinetti ME, Richman D, Powell L. Falls efficacy as a measure of fear of falling. $J$ Gerontol 1990; 45: 239-43.

[28] Yardley L, Smith H. A prospective study of the relationship between feared consequences of falling and avoidance of activity in community-living older people. Gerontologist. 2002; 42: 17-23.

[29] Tinetti ME, Mendes de Leon CF, Doucette JT, Baker DI. Fear of falling and fall-related efficacy in relationship to functioning among community-living elders. J Gerontol 1994; 49(3): M140-M7.

[30] Hill KD, Schwarz JA, Kalogeropoulos AJ, Gibson, SJ. Fear of falling revisited. Arch Phys Med Rehabil 1996; 77: 1025-29.

[31] Mendes de Leon CF, Seeman TE, Baker DI, Richardson ED, Tinetti ME. Self-efficacy, physical decline, and change in functioning in community-living elders: A prospective study. J Gerontol B Psychol Sci Soc Sci 1996; 51B: S183-S90.

[32] Cumming RG, Salkeld G, Thomas M, Szony G. Prospective study of the impact of fear of falling on activities of daily living, SF36 scores, and nursing home admission. J Gerontol A Biol Sci Med Sci 2000; 55: M299-M305.

[33] Petrella RJ, Payne M, Myers A, Overend T, Chesworth B. Physical function of fear of falling after hip fracture rehabilitation in the elderly. Am J Phys Med Rehabil 2000; 79: 154-60.

[34] Wolf SL, Barnhart HX, Kutner NG, McNeely E, Coogler C, Xu T, Atlanta Ficsit Group. Reducing frailty and falls in older persons: an investigation of tai chi and computerized balance training. $J \mathrm{Am}$ Geriatr Soc 1996; 44: 489-97.

[35] Cameron ID, Stafford B, Cumming RG, Birks C, Kurrle SE, Lockwood K, Quine S, Finnegan T, Salkeld G. Hip protectors improve falls self-efficacy. Age Ageing 2000; 29: 57-62.

[36] Tennstedt S, Howland J, Lachman M, Peterson E, Kasten L, Jette A. A randomized, controlled trial of a group intervention to reduce fear of falling and associated activity restriction in older adults. J Gerontol B Psychol Sci Soc Sci 1998; 53: S384-S392.
[37] McKee KJ, Orbell S, Austin CA, Bettridge R, Liddle BJ, Morgan K, Radley K. Fear of falling, falls efficacy and health outcomes in older people following hip fracture. Disabil Rehabil 2002; 6: 327-33.

[38] Stel VS, Pluijm SM, Deeg DJ, Smit JH, Bouter LM, Lips P. A classification tree for predicting recurrent falling in communitydwelling older persons. J Am Geriatr Soc 2003; 51: 1356-64.

[39] Lachman ME, Howland J, Tennstedt S, Jette A, Assmann S, Peterson EW. Fear of falling and activity restriction: the survey of activities and fear of falling in the elderly (SAFE). $J$ Gerontol $B$ Psychol Sci Soc Sci 1998; 53: S43-S50.

[40] Greenberg SA. Assessment of fear of falling in older adults: The Falls Efficacy Scale-International (FES-I). The Hartford Institute for Geriatric Nursing 2011. Available from: https://consultgeri.org/try-this/general-assessment/issue-29.pdf.

[41] Delbaere K, Close JT, Mikolaizak AS, Sachdev PS, Brodaty H, Lord SR. (2010). The Falls Efficacy Scale International (FES-I). A comprehensive longitudinal validation study. Age Ageing 2010; 39: 210-216.

[42] Sevene TG, Berning J, Harris C, Climstein M, Adams KJ, DeBeliso M. Hand grip strength and gender: Allometric normalization in older adults and implications for the NIOSH Lifting Equation. Journal of Lifestyle Medicine 2017; 7: 63-8.

[43] Jaric S, Mirkov D, Markovic G. Normalizing physical performance tests for body size: a proposal for standardization. $J$ Strength Cond Res 2005; 19: 467-74.

[44] Maranhao Neto GA, Oliveira AJ, Pedreiro RC, Pereira-Junior PP, Machado S, Marques Neto S, Farinatti PT. Normalizing handgrip strength in older adults: An allometric approach. Arch Gerontol Geriatr 2017; 70: 230-4.

[45] Cohen J. Statistical Power Analysis for the Behavioral Sciences. (2nd ed.) Lawrence Erlbaum Associates; (NJ). 1988.

[46] Fuller GF. Falls in the elderly. Am. Fam. Physician 2000; 61: 2159-68 (2173-2154).

[47] Gelbard R, Inaba K, Okoye OT, Morrell M, Saadi Z, Lam L, Talving P, Demetriades D. Falls in the elderly: a modern look at an old problem. Am. J. Surg 2014; 208: 249-53.

[48] Barberger-Gateau P, Rainville C, Letenneur L, Dartigues J. A hierarchical model of domains of disablement in the elderly: a longitudinal approach. Disabil Rehabil 2000; 22: 308-17.

[49] Lee M, Hsu C, Tsai Y, Chen C, Lin C, Wang C. Criterionreferenced values of grip strength and usual gait speed using instrumental activities of daily living disability as the criterion. J Geriatr Phys Ther 2018; 41: 14-19.

[50] Frontera WR, Hughes VA, Fielding RA, Fiatarone MA, Evans WJ, Roubenoff R. Aging of skeletal muscle: a 12-yr longitudinal study. J Appl Physiol 2000; 88: 1321-26.

[51] Goodpaster BH, Chomentowski P, Ward BK, Rossi A, Glynn NW, Delmonico MJ, Kritchevsky SB, Pahor M, Newman AB. Effects of physical activity on strength and skeletal muscle fat infiltration in older adults: a randomized controlled trial. [Randomized Controlled Trial Research Support, N.I.H., Extramural]. J. Appl. Physiol 2008; 105: 1498-1503.

[52] Pluijm SM, Smit JH, Tromp E, Stel V, Deeg DJ, Bouter L, Lips P. A risk profile for identifying community-dwelling elderly with a high risk of recurrent falling: results of a 3-year prospective study. Osteoporos Int 2006; 17: 417-25.

[53] Ueno M, Kawai S, Mino T, Kamoshita H. Systematic review of fall-related factors among the house-dwelling elderly in Japan. Nihon Ronen Igakkai Zasshi Jpn J Geriatr 2006; 43: 92-101.

[54] Li R, Xia J, Zhang XI, Gathirua-Mwangi WG, Guo J, Li Y, McKenzie S, Song Y. Associations of muscle mass and strength with all-cause mortality among US older adults. Med Sci Sports Exerc 2018; 50: 458-67.

[55] Chipperfield, J. G. Everyday Physical Activity as a Predictor of Late-Life Mortality. Gerontologist 2008; 48: 349-57.

[56] Zhang JG, Ishikawa-Takata K, Yamazaki H, Morita T, Ohta, T. The effects of Tai Chi Chuan on physiological function and fear of falling in the less robust elderly: an intervention study for preventing falls. Arch Gerontol Geriatr 2006; 42: 107-116. (PMID:16125805).

[57] Chen IJ, Huang LH, Cheng SP. Trends of exercise training research in fall prevention programs among the elderly. Taiwan Journal of Public Health 2005; 24: 93-102.

[58] EI-Khoury F, Cassou B, Charles MA, Dargent-Molina P. The effect of fall prevention exercise programmes on fall induced 
injuries in community dwelling older adults: Systematic review and meta-analysis of randomized controlled trials. Br Med J 2013; 347: f6234.

[59] Huang TT, Yang LH, Liu CY. Reducing the fear of falling through cognitive-behavioural strategies and intense Tai Chi exercise among community-dwelling elderly adults: A randomised controlled trial. J Adv Nurs 2011; 67: 961-71.
[60] Concannon LG, Grierson MJ, Harrast MA. Exercise in the older adult: From the sedentary elderly to the masters athlete. $P m \& r$ 2012; 4: 833-9.

[61] DeBeliso MA, McChesney JW, Murdock LE. Grip norms and reliability of the hand grip ForceMap system. J Hand Surg Eur Vol. 2013 Nov; 38(9): 1009-10. 